\title{
Spectroscopy Studies on Stream Sediments in the Terahertz Range
}

\author{
Chen Chen ${ }^{1,2}$, Jinsong Liu ${ }^{1}$, Jianquan Yao1,3 \\ ${ }^{1}$ Wuhan National Laboratory for Optoelectronics, School of Optical and Electronic Information, \\ Huazhong University of Science and Technology, Wuhan, China \\ ${ }^{2}$ School of Physics and Optoelectronic Engineering, Yangtze University, Institute of Photoelectric Technology, \\ Jingzhou, China \\ ${ }^{3}$ Institute of Laser and Opto-Electronics, School of Precision Instrument and Optoelectronics Engineering, \\ Tianjin University, Tianjin , China \\ Email: chenchen@yangtzeu.edu.cn, ${ }^{*}$ jsliu4508@vip.sina.com
}

Received 30 May 2016; accepted 21 August 2016; published 25 August 2016

\begin{abstract}
In order to study stream sediments in the terahertz range, we have measured six reference stream sediment samples by terahertz time-domain spectroscopy (THz-TDS). We obtained the absorption coefficients and refractive indexes. By analyzing the spectra, we got different drops in amplitude and delays in time. The absorption and refractive properties of samples changed with its components and types. In addition, we also found there was a nearly linear relationship between the absorption coefficient and the frequency. We calculated the slope value (K) of each sample by linear fitting, and find the $K$ was corresponding to the contents of the samples. The results showed THz-TDS was an effective method to the analysis of stream sediments.
\end{abstract}

\section{Keywords}

Terahertz Time-Domain Spectroscopy, Stream Sediments, Absorption Coefficient, Refractive Index

\section{Introduction}

Along with the technical progress, many new technologies and methods are applied to the determination of stream sediment [1]. Terahertz time-domain spectroscopy (THz-TDS), which ranges from 0.1 to $10 \mathrm{THz}$, contains rich physical, chemical, and structural information of the materials. According to many advantages compared with classic spectroscopy, THz-TDS has been widely used in the field of analysis and testing [2]-[12].

In this paper, the application of THz-TDS in stream sediments is reported. Refractive index and absorption coefficient spectra are calculated. By analyzing the spectra, we get different drops in amplitude and delays in time. The absorption and refractive properties of samples are changed with its components and types. In addition, we also find that there is a nearly linear relationship between the absorption coefficient and the frequency. We calculate the slope value of each sample by linear fitting, and find it is corresponding to the contents of the sam-

${ }^{*}$ Corresponding author. 
ples. The results show THz-TDS is an effective method to the analysis of stream sediments, and it will have a bright future in this field.

\section{Experimental}

\subsection{Sample Preparation}

Six kinds of reference stream sediment materials are in powder. They have large THz absorption, while PE (Polytene) powder has little absorption effect in THz range. The PE was employed to blend the stream sediment materials. The stream sediment materials were mixed by PE with the mass ratio equaling $1: 1$, and then were pressed to pellets. The pressure and the time length in the pressing process were $25 \mathrm{MPa}$ and $2 \mathrm{~min}$, respectively. Six kinds of tables with the thickness about $1.20 \mathrm{~mm}$ and the diameter of $13 \mathrm{~mm}$ were obtained for THz measurement. The information of samples is according to the given data in Table 1. All the samples have been using inductively coupled plasma mass spectrometry (icp-ms), inductively coupled plasma atomic emission spectrometry (icp-aes), atomic absorption spectrum (AAS), atomic fluorescence analysis method (AFS), and other methods. The composition and content of components information is already known (in Table 2) before the experiment.

\subsection{THz-TDS Setup and Measurement Condition}

The experimental setup we used is comprised of a commercial mode-locked fem to second Ti: sapphire laser and a transmission THz-TDS system. The principle and instrument parameters refer to literature [13]. The fem to second laser, producing $100 \mathrm{fs}$ pulses at $800 \mathrm{~nm}$ with a $1000 \mathrm{~Hz}$ repetition rate, pumps the antennas for generating and detecting $\mathrm{THz}$ pulses. In order to prevent absorption by atmospheric water vapor in $\mathrm{THz}$ range, the setup was covered with high-purity, dry nitrogen at room temperature $(294 \mathrm{~K})$. The relative humidity is less than $2 \%$ during the measurement.

Table 1. The information of six samples of stream sediments.

\begin{tabular}{ccc}
\hline Number & Reference materials & Thickness (mm) \\
\hline 1 & GBW07123 & 1.20 \\
2 & GBW07309 & 1.18 \\
3 & GBW07405 & 1.24 \\
4 & GBW07304a & 1.16 \\
5 & GBW07301a & 1.18 \\
6 & GBW07408 & 1.26 \\
\hline
\end{tabular}

Table 2. The component and weight ratio of six samples of stream sediments.

\begin{tabular}{cccccccccccc}
\hline \multicolumn{10}{c}{ Number } & \multicolumn{10}{c}{ Component and weight ratio (\%) } \\
\cline { 2 - 5 } & $\mathrm{Al}_{2} \mathrm{O}_{3}$ & $\mathrm{CaO}$ & $\mathrm{FeO}$ & $\mathrm{K}_{2} \mathrm{O}$ & $\mathrm{MgO}$ & $\mathrm{Na}_{2} \mathrm{O}$ & $\mathrm{SiO}_{2}$ & $\mathrm{Fe}_{2} \mathrm{O}_{3}$ & $\mathrm{CO}_{2}$ & $\mathrm{H}_{2} \mathrm{O}^{+}$ \\
\hline 1 & $13.21 \pm 0.08$ & $7.83 \pm 0.13$ & $7.24 \pm 0.21$ & $1.49 \pm 0.08$ & $5.08 \pm 0.07$ & $3.17 \pm 0.10$ & $49.88 \pm 0.22$ & $13.40 \pm 0.21$ & $(0.11)$ & $(2.44)$ \\
2 & $10.58 \pm 0.15$ & $5.35 \pm 0.14$ & $1.53 \pm 0.07$ & $1.99 \pm 0.08$ & $2.39 \pm 0.09$ & $1.44 \pm 0.06$ & $64.89 \pm 0.16$ & $4.86 \pm 0.11$ & $4.20 \pm 0.11$ & $2.93 \pm 0.27$ \\
3 & $21.58 \pm 0.23$ & $(0.095)$ & $(0.22)$ & $1.50 \pm 0.06$ & $0.61 \pm 0.08$ & $0.12 \pm 0.03$ & $52.57 \pm 0.25$ & $12.62 \pm 0.27$ & $(0.10)$ & $(8.8)$ \\
4 & $10.94 \pm 0.06$ & $0.82 \pm 0.03$ & $(0.85)$ & $1.51 \pm 0.03$ & $0.60 \pm 0.02$ & $0.34 \pm 0.22$ & $73.85 \pm 0.35$ & $4.55 \pm 0.10$ & $(0.4)$ & $(4.3)$ \\
5 & $15.4 \pm 0.1$ & $4.0 \pm 0.1$ & $(2.4)$ & $2.8 \pm 0.1$ & $3.30 \pm 0.12$ & $3.4 \pm 0.1$ & $59.2 \pm 0.02$ & $6.50 \pm 0.12$ & $(0.07)$ & $(2.7)$ \\
6 & $11.92 \pm 0.23$ & $8.27 \pm 0.18$ & $1.22 \pm 0.07$ & $2.42 \pm 0.06$ & $2.38 \pm 0.10$ & $1.72 \pm 0.06$ & $58.61 \pm 0.20$ & $4.48 \pm 0.07$ & $5.97 \pm 0.02$ & $(3.3)$ \\
\hline
\end{tabular}




\section{Results and Discussion}

We obtained the optical properties of the six kinds of reference stream sediment materials in terahertz range. Figure 1 shows the THz field signal. The reference pulse was obtained by scanning the empty cell firstly, and the waveforms of all the samples' spectra were varying from each other as shown in Figure 1(a). The reference signal of free space with no sample is in the left. The other lines are the samples' spectra. Different sample causes a unique waveform, including different delay, the amplitude, and peak time, etc. It indicates that $\mathrm{THz}$ technique could give the amplitude and phase information of samples simultaneously.

A fast Fourier transform (FFT) was applied to obtain the THz frequency domain spectra (THz-FDS). As showed in Figure 1(b), due to the strong absorption, the effective frequency range was reduced to 0.1 - 1.2 THz. The observations from the $\mathrm{THz}$ waveforms show the intensity decreased in a similar trend with an increase in frequency.

Using Equations (1)-(3), the absorption coefficient $\alpha$ and the refractive index $n$ can be calculated: [14]-[16]

$$
\begin{gathered}
k(v)=\frac{c}{2 \pi v d} \ln \frac{4 n(v)}{A(1+n(v))^{2}} \\
\alpha(v)=\frac{4 \pi v k(v)}{c} \\
n(v)=1+\frac{c \varphi}{2 \pi v d}
\end{gathered}
$$

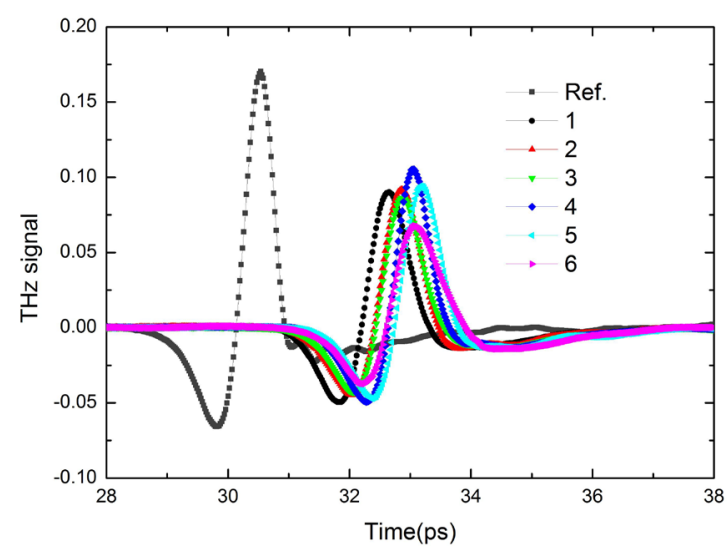

(a)

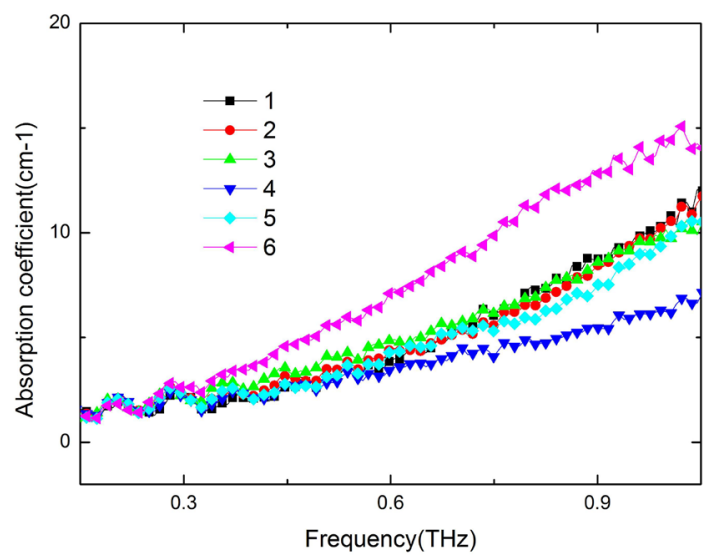

(c)

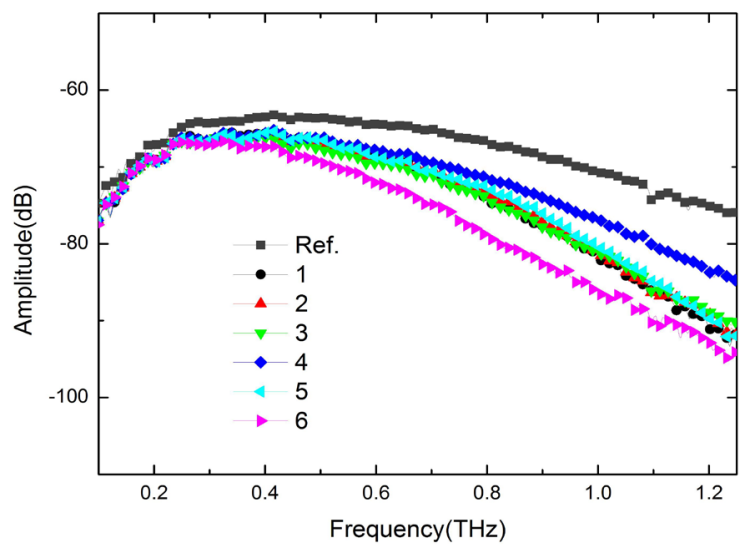

(b)

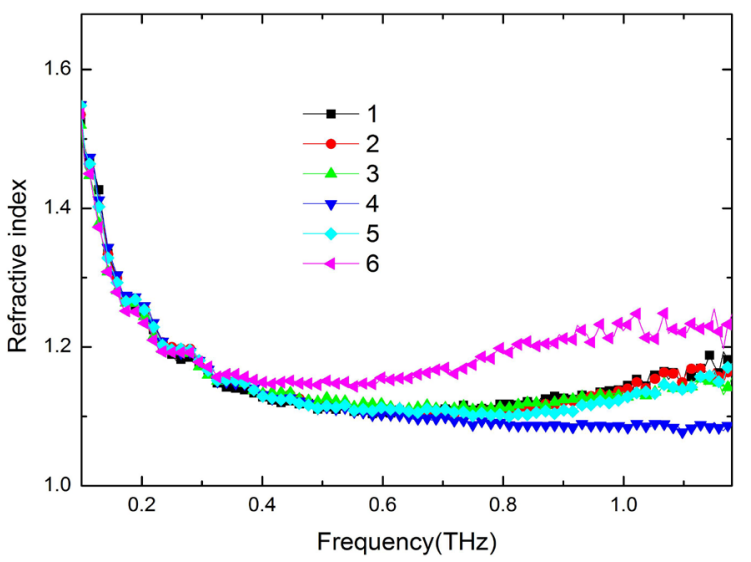

(d)

Figure 1. (a) Time dependence of THz signal spectra of reference and six samples; (b) The frequency dependent absorbance spectra in 0.1 - $1.2 \mathrm{THz}$; (c) Absorption coefficient spectra of six samples; (d) Refractive index spectra of six samples. 
where $d$ denotes sample thickness, $\varphi$ represents the difference in phase shift between sample and reference, $c$ is the speed of light, $A$ is the frequency-dependent amplitude. The absorption coefficient spectra and the frequency-dependent refractive indices of six samples are in Figure 1(c) and Figure 1(d), respectively. Results show that the thicker the sample is, the larger the refractive index $n$ is. The absorption coefficient decreases with the increase of refractive index.

Figure 1(c) shows there is an approximately linear relationship between the absorption coefficient and the frequency. According to the experimental data, we calculate the slope value of each sample by linear fitting, and find it is corresponding to the contents of the samples. Figure 2(a) shows the slope of absorption coefficient curve. Figure 2(b) is the components content curve of samples according to Table 2. The ten main compositions were analyzed, including $\mathrm{Al}_{2} \mathrm{O}_{3}, \mathrm{CaO}, \mathrm{FeO}, \mathrm{K}_{2} \mathrm{O}, \mathrm{MgO}, \mathrm{Na}_{2} \mathrm{O}, \mathrm{SiO}_{2}, \mathrm{Fe}_{2} \mathrm{O}_{3}, \mathrm{CO}_{2}$ and $\mathrm{H}_{2} \mathrm{O}^{+}$. The slope curve has a sudden change in $4 \#$ sample, while the content of $\mathrm{SiO}_{2}$ in all the samples is the highest.

\section{Conclusion}

In summary, THz-TDS was used to analyze six kinds of stream sediments. The time-domain spectrum, absorption spectrum and refractive index were obtained. Through the further analysis of the spectrum, we found the spectral information was corresponding to the contents of the samples. The results show THz-TDS is a potential method to the analysis of stream sediments, and it will have a bright future in this field.

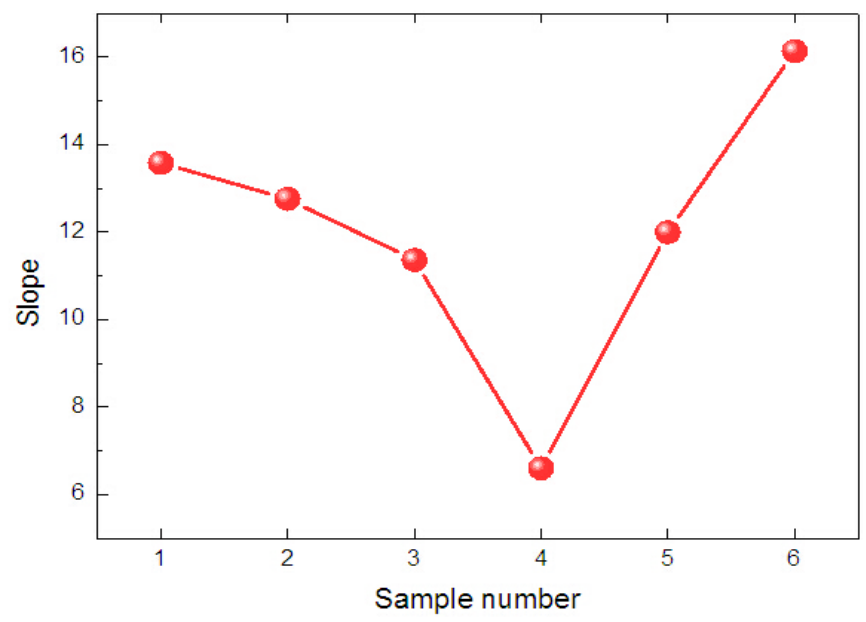

(a)

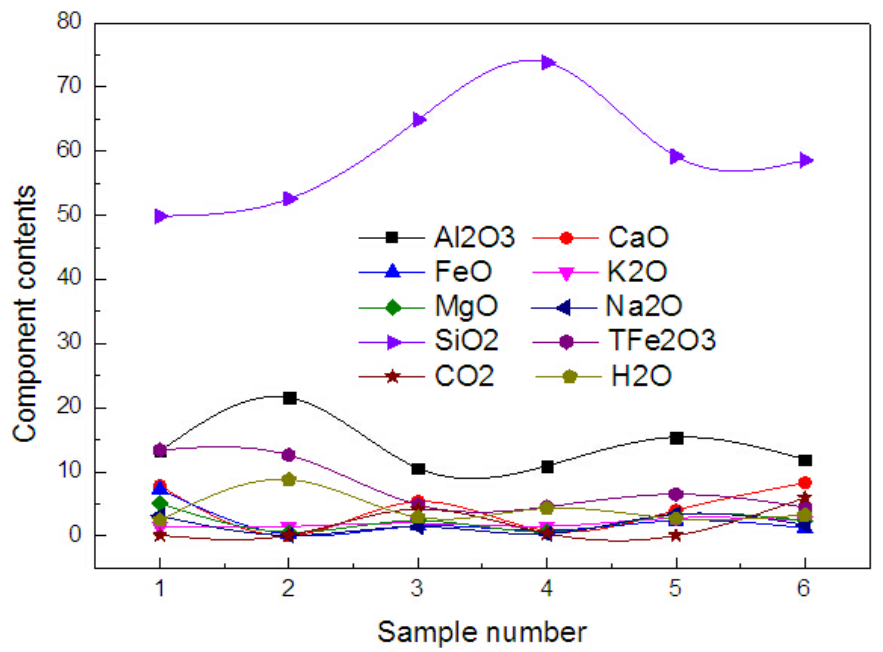

(b)

Figure 2. (a) The slope of absorption coefficient curve; (b) The components content of samples. 


\section{Acknowledgements}

This research is supported by the Yangtze Youth Fund of Yangtze University (No. 2015cqn74).

The authors want to thank Prof. Kun Zhao, Honglei Zhan, Chen Jiang and Xinyang Miao at Beijing Key Laboratory of Optical Detection Technology for Oil and Gas (China University of Petroleum) for their help in experiment, and Prof. Yangen Wang, Shaolong Wang at School of Physics and Optoelectronic Engineering (Yangtze University) for their help in samples.

\section{References}

[1] Hunt, A.M.W., Dvoracek, D.K., Glascock, M.D. and Speakman, R.J. (2014) Major, Minor and Trace Element Mass Fractions Determined Using ED-XRF, WD-XRF and INAA for Five Certified Clay Reference Materials: NCS DC 60102-60105; NCS DC 61101 (GBW 03101A, 03102A, 03103, and 03115). Journal of Radioanalytical \& Nuclear Chemistry, 302, 505-512. http://dx.doi.org/10.1007/s10967-014-3266-z

[2] Horiuchi, N. (2010) Searching for Terahertz Waves. Nature Photonics, 4, 662. http://dx.doi.org/10.1038/nphoton.2010.216

[3] Karpowicz, N., Dai, J., Lu, X., Chen, Y., Yamaguchi, M., Zhao, H., et al. (2008) Coherent Heterodyne Time-Domain Spectrometry Covering the Entire “Terahertz Gap”. Applied Physics Letters, 92, 011131. http://dx.doi.org/10.1063/1.2828709

[4] Jiang, C., Zhao, K., Zhao, L.J., et al. (2014) Probing Disaggregation of Crude Oil in a Magnetic Field with Terahertz Time-Domain Spectroscopy. Energy Fuels, 28, 483-487. http://dx.doi.org/10.1021/ef401984u

[5] Bao, R., Wu, S., Zhao, K., et al. (2013) Applying Terahertz Time-Domain Spectroscopy to Probe the Evolution of Kerogen in Close Pyrolysis Systems. Science China Physics, Mechanics and Astronomy, 56, 1603-1605. http://dx.doi.org/10.1007/s11433-013-5085-6

[6] Jin, W., Zhao, K., Yang, C., et al. (2013) Experimental Measurements of Water Content in Crude Oil Emulsions by Terahertz Time-Domain Spectroscopy. Applied Geophysics, 10, 506-509. http://dx.doi.org/10.1007/s11770-013-0404-2

[7] Bao, R.M., Tian, L., Zhao, K., et al. (2011) Spectroscopy Studies on the Tuha Crude Oil in the Terahertz Range. SPIE Proceedings, 8195, 81951J. http://dx.doi.org/10.1117/12.900988

[8] Qin, F., Li, Q., Zhan, H., et al. (2014) Probing the Sulfur Content in Gasoline Quantitatively with Terahertz TimeDomain Spectroscopy. Science China Physics, Mechanics and Astronomy, 57, 1404-1406. http://dx.doi.org/10.1007/s11433-014-5409-1

[9] Tian, L., Zhou, Q., Jin, B., et al. (2009) Optical Property and Spectroscopy Studies on the Selected Lubricating Oil in the Terahertz Range. Science in China (Series G: Physics), 52, 1938-1943. http://dx.doi.org/10.1007/s11433-009-0310-z

[10] Zhao, H., Zhao, K. and Bao, R. (2012) Fuel Property Determination of Biodiesel-Diesel Blends by Terahertz Spectrum. Journal of Infrared, Millimeter and Terahertz Waves, 33, 522-528. http://dx.doi.org/10.1007/s10762-012-9886-X

[11] Leng, W.X., Ge, L.N., Xu, S.S., et al. (2014) Pressure-Dependent Terahertz Optical Characterization of Heptafluoropropane. Chin. Phys. B, 23, 107804. http://dx.doi.org/10.1088/1674-1056/23/10/107804

[12] Marquez, E., Ramirezmalo, J., Villares, P., Jimenezgaray, R., Ewen, P.J.S. and Owen, A.E. (1992) Calculation of the Thickness and Optical Constants of Amorphous Arsenic Sulphide Films from Their Transmission Spectra. Enfermedades Infecciosas Y Microbiología Clínica, 139, 237-248. http://dx.doi.org/10.1088/0022-3727/25/3/031

[13] Li, J.S. (2010) Optical Parameters of Vegetable Oil Studied by Terahertz Time-Domain Spectroscopy. Applied Spectroscopy, 64, 231-234. http://dx.doi.org/10.1366/000370210790619663

[14] Duvillaret, L., Garet, F. and Coutaz, J.L. (1999) Highly Precise Determination of Optical Constants and Sample Thickness in Terahertz Time-Domain Spectroscopy. Applied Optics, 38, 409-415. http://dx.doi.org/10.1364/AO.38.000409

[15] Duvillaret, L., Garet, F. and Coutaz, J.L. (1996) A Reliable Method for Extraction of Material Parameters in Terahertz Time-Domain Spectroscopy. IEEE Journal of Selected Topics in Quantum Electronics, 2, 739-746. http://dx.doi.org/10.1109/2944.571775

[16] Dorney, T.D., Baraniuk, R.G. and Mittleman, D.M. (2001) Material Parameter Estimation with Terahertz Time-Domain Spectroscopy. Journal of the Optical Society of America A: Optics Image Science \& Vision, 18, 1562-1571. http://dx.doi.org/10.1364/JOSAA.18.001562 


\section{Submit or recommend next manuscript to SCIRP and we will provide best service for you:}

Accepting pre-submission inquiries through Email, Facebook, LinkedIn, Twitter, etc.

A wide selection of journals (inclusive of 9 subjects, more than 200 journals)

Providing 24-hour high-quality service

User-friendly online submission system

Fair and swift peer-review system

Efficient typesetting and proofreading procedure

Display of the result of downloads and visits, as well as the number of cited articles

Maximum dissemination of your research work

Submit your manuscript at: http://papersubmission.scirp.org/ 